\title{
Probability Model of Hangzhou Bay Bridge Vehicle Loads Using Weigh-in-Motion Data
}

\author{
Dezhang Sun, ${ }^{1}$ Xu Wang, ${ }^{2}$ Bin Chen, ${ }^{3}$ and Baitao Sun ${ }^{1}$ \\ ${ }^{1}$ Institute of Engineering Mechanics, China Earthquake Administration, Harbin 150080, China \\ ${ }^{2}$ State Key Laboratory Breeding Base of Mountain Bridge and Tunnel Engineering, Chongqing Jiaotong University, \\ Chongqing 400074, China \\ ${ }^{3}$ College of Civil Engineering and Architecture, Zhejiang University, Hangzhou 310058, China
}

Correspondence should be addressed to Xu Wang; wx00012224@163.com

Received 7 August 2014; Accepted 6 February 2015

Academic Editor: Gangbing Song

Copyright (C) 2015 Dezhang Sun et al. This is an open access article distributed under the Creative Commons Attribution License, which permits unrestricted use, distribution, and reproduction in any medium, provided the original work is properly cited.

To study the vehicle load characteristics of bay bridges in China, especially truck loads, we performed a statistical analysis of the vehicle loads on Hangzhou Bay Bridge using more than 3 months of weigh-in-motion data from the site. The results showed that when all the vehicle samples were included in the statistical analysis, the histogram of the vehicles exhibited a multimodal distribution, which could not be fitted successfully by a familiar single probability distribution model. When the truck samples were analyzed, a characteristic multiple-peaked distribution with a main peak was obtained. The probability distribution of all vehicles was fitted using a weighting function with five normal distributions and the truck loads were modeled by a single normal distribution. The results demonstrated the good fits with the histogram. The histograms of different time periods were also analyzed. The results showed that the traffic mainly comprised two-axle small vehicles during the rush hours in the morning and the evening, and the histogram could be fitted approximately using three normal distribution functions. And the maximum value distributions of vehicles during the design life of the bay bridge were predicted by maximum value theory.

\section{Introduction}

The rapid economic development of China is reflected by the construction of large-span bridges in recent decades. Over 60 bridges with spans of $>400 \mathrm{~m}$ have been built [1], including several super-large bay bridges, for example, Jiaozhou Bay Bridge [2], Hangzhou Bay Bridge [3], and the cross-sea bridge of Hongkong-Zhuhai-Macao, which is under construction. These bridges play an important role in the development of regional economies, but the dramatic increases in traffic volume will become more severe with growing economic development, especially in some big cities, which may affect the safety of bridges and decrease the normal service life of these structures. In the Yangtze River Delta region, bridges have exhibited problems such as cracking and long-term deflection due to the effects of high traffic. Thus, it is necessary to determine the actual vehicle loads of bridges to provide a reference for the assessment of other bridges in the region.
Many previous studies have addressed vehicle loads. Studies of vehicle loads have been performed outside China for many years, but they have been continued as the traffic loads have increased. These studies only began recently in China, mainly because suitable weighing equipment was rarely available in the past and limited data were acquired. At present, newly built long-span bridges must be equipped with health monitoring systems to monitor the bridge situation $[4,5]$. In addition, bridge destruction due to high vehicle loads was rare in the past. However, with the development of the economy, traffic volumes have increased dramatically and the frequencies of heavy vehicles have increased greatly. Based on truck data collected in Ontario, Nowak [6] used the HL-93 truck model to analyze the effects of different truck numbers, bridge lengths and widths on the maximum bending moment, shearing force, and hogging moment of a bridge. Nowak also studied the effects of the dynamic 
response of trucks on the bridge and determined the relationship between the truck loads with different lane numbers. Finally, the truck load factor for the load and resistance factor design (LRFD) specification was obtained. Moses [7] found that the truck load adopted in the American Association of State Highway and Transportation Officials (AASHTO) specifications agreed approximately with a normal distribution, where the mean value was $300 \mathrm{kN}$ and the coefficient of variation was $26.5 \%$, which were not inconsistent with those of the LRFD. Based on data collected for vehicles, Fu and You $[8,9]$ analyzed the vehicle load statistics characteristics and determined the possible maximum value distribution of vehicles during a bridge service life using the extreme value theory, where they obtained the vehicle load factor by reliability index analysis. Based on WIM data for vehicles from two European sites, Obrien et al. [10] studied the effects of various parameters on the fitted results in a truck load model and demonstrated the high sensitivity of the fit. Based on truck data from three sites in Indiana, USA, Chotickai and Bowman [11] developed a truck model based on the fatigue damage analysis of steel. Zhao and Tabatabai [12] also analyzed a standard common vehicle model for the region using six million vehicle samples obtained from Washington, USA.

Using statistical data for the current vehicle loads on National Expressway 110, Mei et al. [13] discussed the characteristic probability distribution of a large number of overloaded vehicles and regular vehicles. They obtained a vehicle load histogram with a multiple-peaked probability distribution, which was weighted based on two normal distributions. After investigating overloaded vehicles transporting coal on Gudianta road in Shanxi Province, China, Zong et al. [14] classified the overloaded vehicles according to nine types based on the loading and axle types of the vehicles, as well as analyzing the overloading and overloading limits for each type of vehicle, thereby determining the relationship between overloading and the overloading limits using linear regression. Based on actual measurements and statistical analysis of the running conditions of vehicles on the BeijingShanghai highway, Guo et al. [15] found that the vehicle loads histogram exhibited a characteristic multimodal distribution and they obtained a probabilistic model by curve fitting. Based on the statistical analysis of vehicle load data from several regions, such as uncontrolled overloading, weighing charges, and controlling overloading by constraints, Gong et al. [16] found that the loads of vehicles passing along all roads exhibited multimodal distribution features. Based on data obtained from the traffic axle loads measured using a WIM system, Xu et al. [17] obtained appropriate vehicle load parameters for the actual traffic conditions in Guangdong Province. They found that the measured total weights and axle weights of vehicle loads in Guangdong Province were all higher than the values specified in the regulations. Using basic information for traffic operations acquired by a WIM system, S. W. Sun and L. M. Sun [18] studied the characteristic parameter distributions of many vehicle loads, such as the axle weight and wheelbase, and derived a practical and simple vehicle-based fatigue model.
These previous studies focused mainly on the vehicle loads of road bridges, including urban bridges. However, the vehicle load conditions of bay bridges are different from both of these types. The vehicle loads of busy road bridges mainly comprise multiaxle heavy trucks, whereas those of urban bridges mainly comprise cars, but the vehicle loads of bay bridges include both types. In the present study, the vehicle loads of Hangzhou Bay Bridge were analyzed. Based on WIM data obtained from Hangzhou Bay Bridge for over 3 months, the vehicle load histograms were determined and a probabilistic model of the truck loads was produced. In addition, the maximum value distribution was predicted for vehicles during the reference design period of bay bridges using the maximum value theory, thereby facilitating a better understanding of the vehicle load distributions of bay bridges. These data can provide a basis for the revision of specifications.

\section{Data Acquisition}

Hangzhou Bay Bridge is a cross-sea bridge that stretches over Hangzhou Bay in China. It officially entered use on May 1, 2008. Its main span is $325 \mathrm{~m}$ and its width is $33 \mathrm{~m}$ with six lanes of traffic in two directions. It extends for $36 \mathrm{~km}$ from Jiaxing City in Zhejiang Province in the north to Ningbo in the south (Figure 1). It is the third longest cross-sea bridge in the world and it is $11 \mathrm{~km}$ longer than King Fahd Bridge, which connects Bahrain with Saudi Arabia. In the plan of the Zhejiang expressway, Hangzhou Bay Bridge is named as "Hangzhou Bay-Ningbo channel," which is one of the "three channels" in the Zhejiang expressway network in the future.

The bridge employs a charging operational mode and the WIM system is embedded near the charging site at both entrances (two directions) to obtain information about vehicles, including the passing time, gross weight, axle weight, wheelbase, axle number, and speed. According to official statistics, there have been up to 19 million passing vehicles since its opening on May 1, 2010, that is, 23,000 per day. In this study, data in the paper were obtained from south entrance WIM system that recording three lane vehicles of the bridge during more than 3 months between September 2012 and January 2013. Before the analysis, the data were preprocessed to remove any obvious errors and meaningless data [19].

\section{Statistical Analysis}

3.1. Probabilistic Characteristics of the All-Vehicle Analysis. After preprocessing, there were 82 effective days and 931,774 valid data points. Initially, the mean values, standard deviations, and maximum values were calculated for the valid data, which showed that the mean values and coefficients of variation for the vehicle loads were relatively concentrated in specific periods, except the coefficients of variation (COV) which were higher on holidays such as New Year's Day, thereby indicating that the vehicle loads were consistent in the short term; some samples are shown in Table 1.

Figures 2 and 3 show the characteristics of the mean values, maximum values, coefficients of variation, and vehicle 


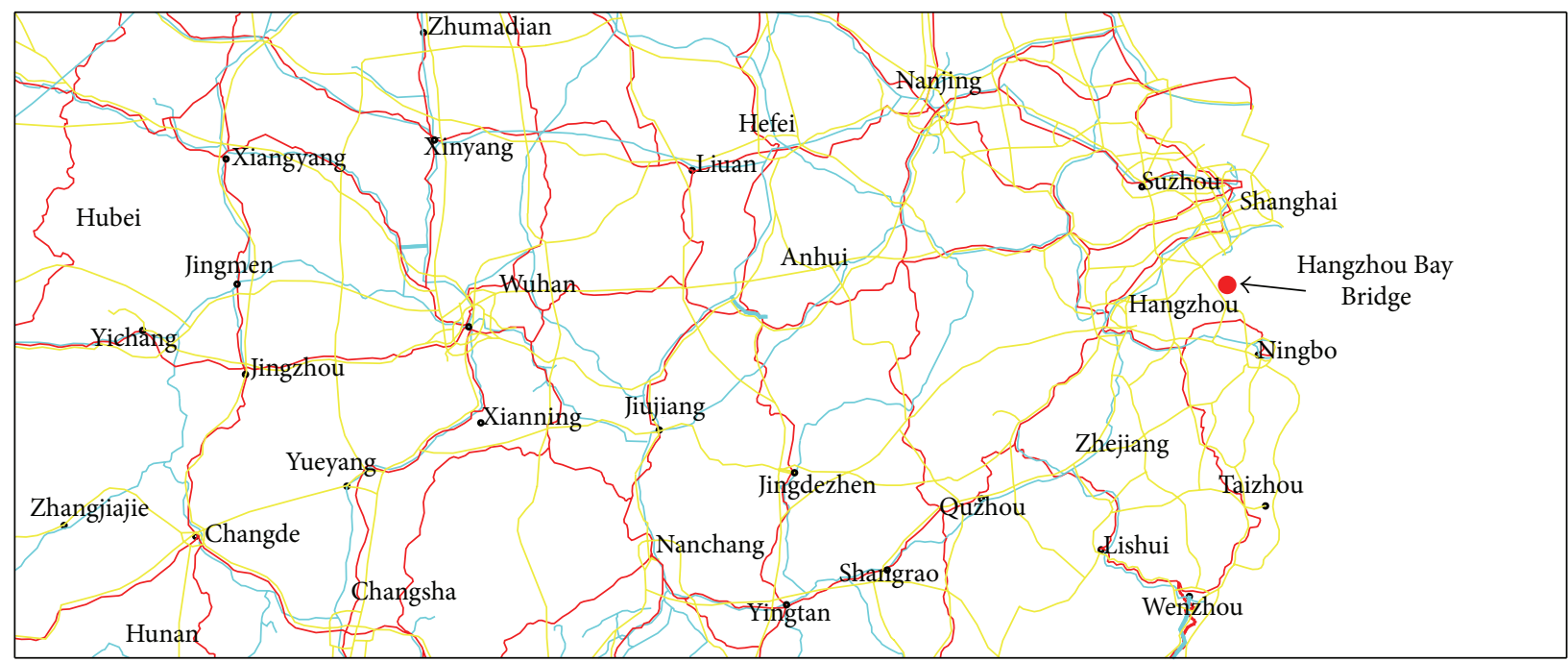

(a)

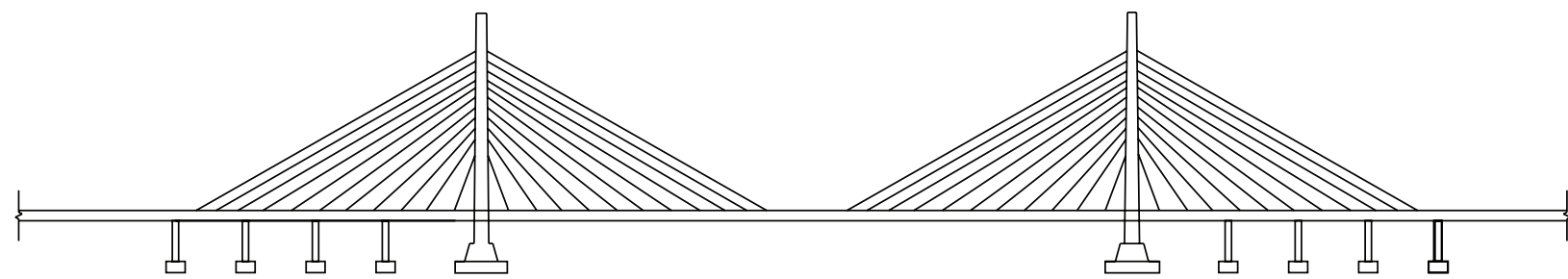

(b)

FIGURE 1: (a) Location of Hangzhou Bay Bridge. (b) Facade profile sketch map of the main towers of Hangzhou Bay Bridge.

TABLE 1: Statistical characteristics of the vehicle loads.

\begin{tabular}{|c|c|c|c|c|c|}
\hline Date & Vehicle number & Mean value/ton & Standard deviation/ton & Coefficient of variation & Maximum value/ton \\
\hline 20120916 & 7408 & 11.29345 & 9.787491 & 0.866652 & 65.5 \\
\hline 20120926 & 7399 & 13.15604 & 10.88008 & 0.827002 & 72.4 \\
\hline 20121102 & 14627 & 7.913687 & 10.33094 & 1.305452 & 72.7 \\
\hline 20121103 & 11351 & 8.199344 & 10.54972 & 1.286654 & 73.5 \\
\hline 20121106 & 13263 & 8.948771 & 11.30286 & 1.263063 & 75.1 \\
\hline 20121107 & 13641 & 8.587805 & 10.70217 & 1.246205 & 80.95 \\
\hline 20121110 & 10426 & 8.58123 & 11.2873 & 1.315347 & 124.4 \\
\hline 20121111 & 11694 & 7.499042 & 9.344368 & 1.246075 & 71.3 \\
\hline 20121112 & 11633 & 8.413505 & 9.937082 & 1.181087 & 71.5 \\
\hline 20121114 & 14232 & 7.807947 & 9.695331 & 1.241726 & 89.2 \\
\hline 20121127 & 12080 & 8.341387 & 10.46041 & 1.254038 & 103.5 \\
\hline 20121128 & 11771 & 8.037461 & 9.97701 & 1.241314 & 102.3 \\
\hline 20130101 & 10459 & 6.523783 & 9.956516 & 1.526187 & 70.4 \\
\hline 20130102 & 10835 & 6.878782 & 10.37906 & 1.508851 & 69.9 \\
\hline
\end{tabular}

Note that the vehicle number of Table 1 is just that of one direction of vehicles compared to the average vehicle number of 23000 per day in two directions.

numbers in terms of time and intensity. Figure 2 shows that the different mean values were relatively concentrated and the maximum values generally fluctuated around $70 \mathrm{t}$, except in a very small number of cases, which demonstrates that some vehicles exceeded the weight limit. Figure 3 shows that the coefficients of variation were almost constant with time and their trends were similar to the vehicle numbers. The higher vehicle numbers were recorded during holidays, which did not reflect the normal vehicle loads.

The vehicle loads of bridges comprised vehicle loads of various type; thus there was a multimodal distribution, which could not be described by familiar probability distributions. If we suppose that $N$ is the main vehicle type that passes over the bridge and the cumulative probability function of 


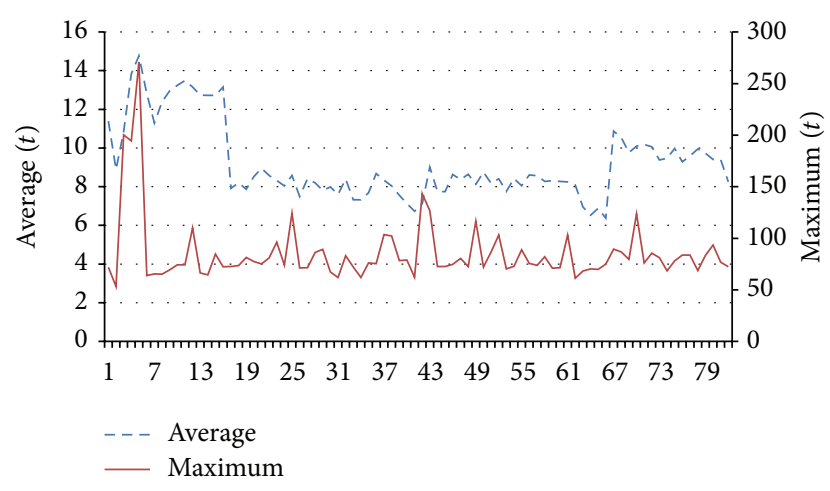

FIgURE 2: Variability in the mean values and maximum values.

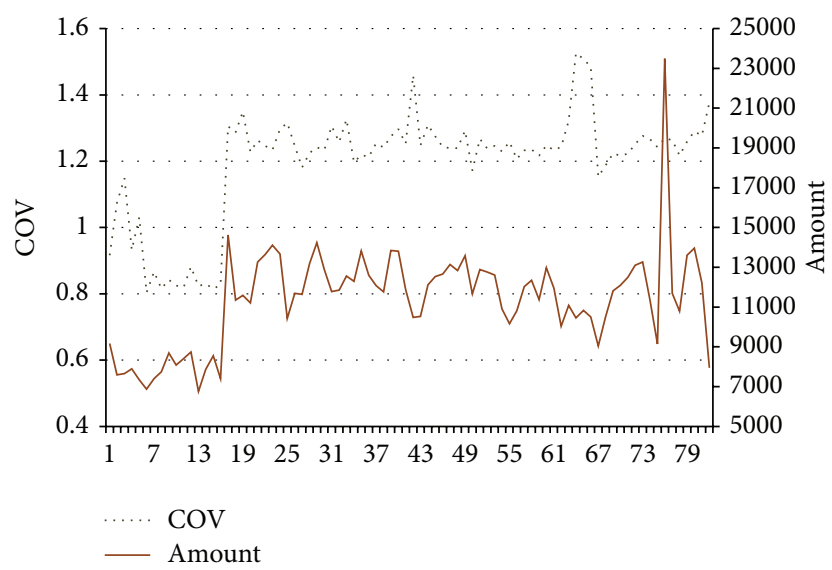

FIGURE 3: Variability in the coefficients of variation and vehicle numbers.

the $i$ th vehicle load is $F_{i}(x)$, then the probability function of the combined vehicle loads can be represented as follows:

$$
F_{X}(x)=\sum_{i=1}^{N} p_{i} \cdot F_{i}(x)
$$

where $p_{i}$ is a weighting coefficient and $\sum_{i=1}^{N} p_{i}=1$.

Based on (1), the probability density function of the combined vehicle loads can be obtained as follows:

$$
f_{X}(x)=\sum_{i=1}^{N} p_{i} \cdot f_{i}(x)
$$

Note that the forms of the cumulative probability distribution and probability density function may differ between (1) and (2), respectively. According to a previous study [7], the probability distribution of vehicle loads can be illustrated using a normal distribution. However, the actual probability histogram exhibited a characteristic multimodal distribution, as shown in Figure 4. The histogram shows the proportions of various vehicles, where the proportion of small vehicles was higher. Therefore, multiple normal distributions were used to fit the histogram. Figures 5-9 show the fitting results obtained using different numbers of normal functions.

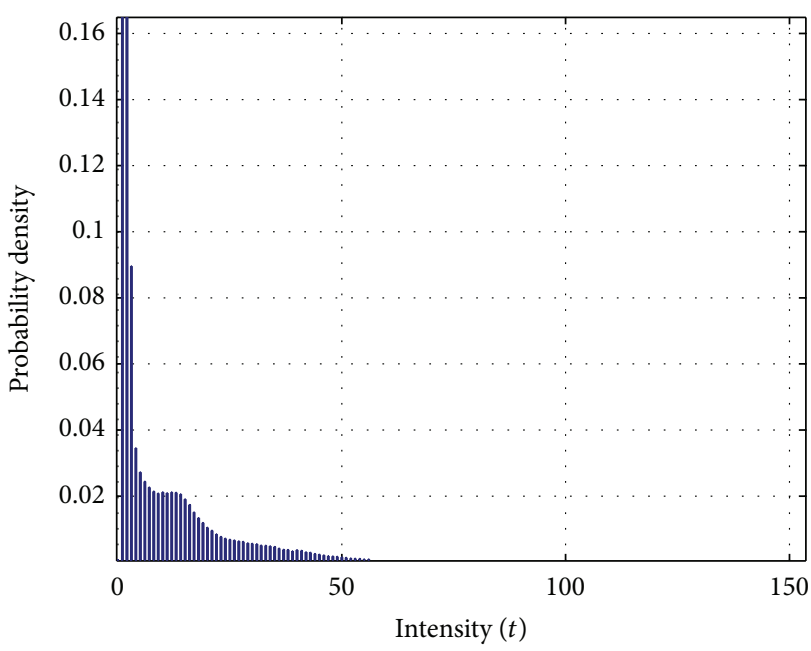

Figure 4: Histogram of the vehicle loads.

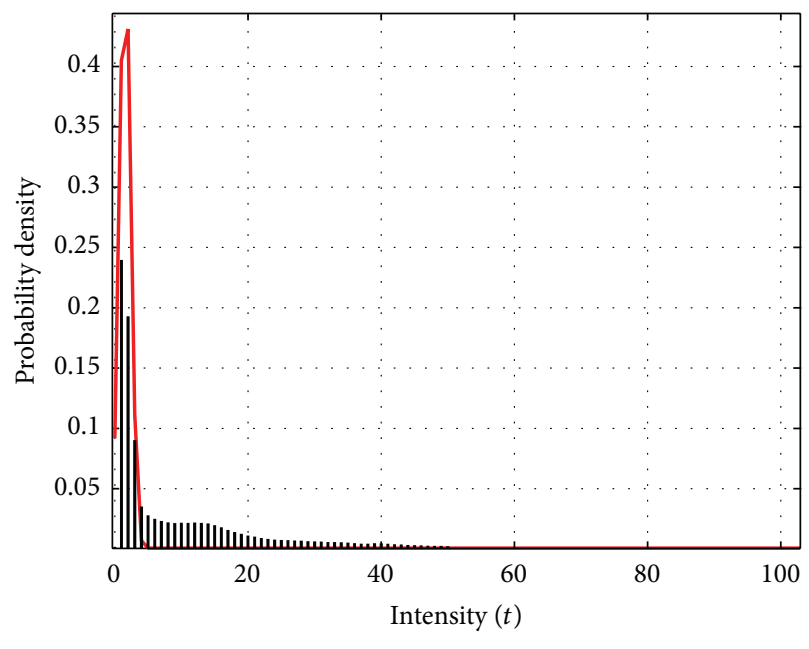

- 1 normal distribution fit

Figure 5: One normal distribution fitted.

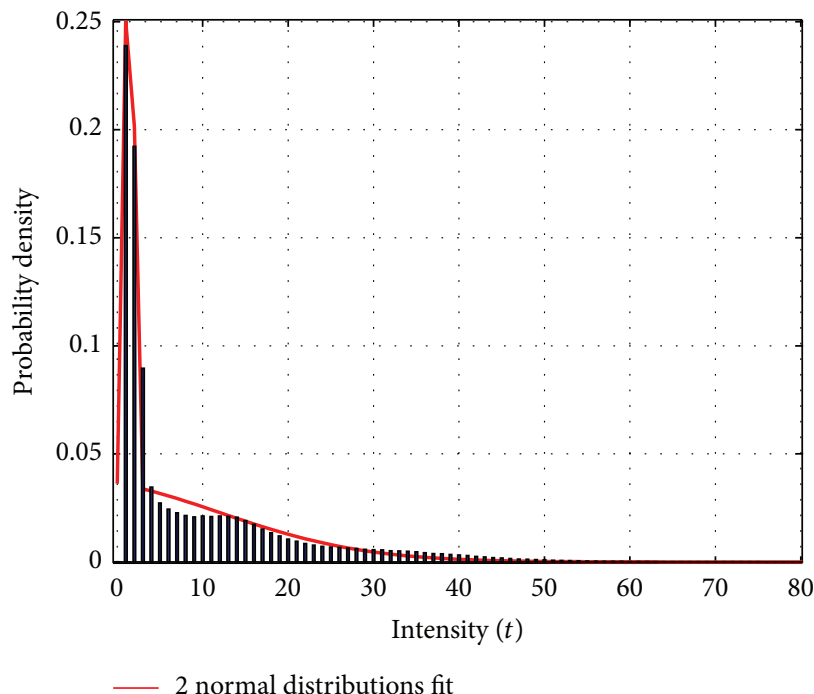

FIgURE 6: Two normal distributions fitted. 


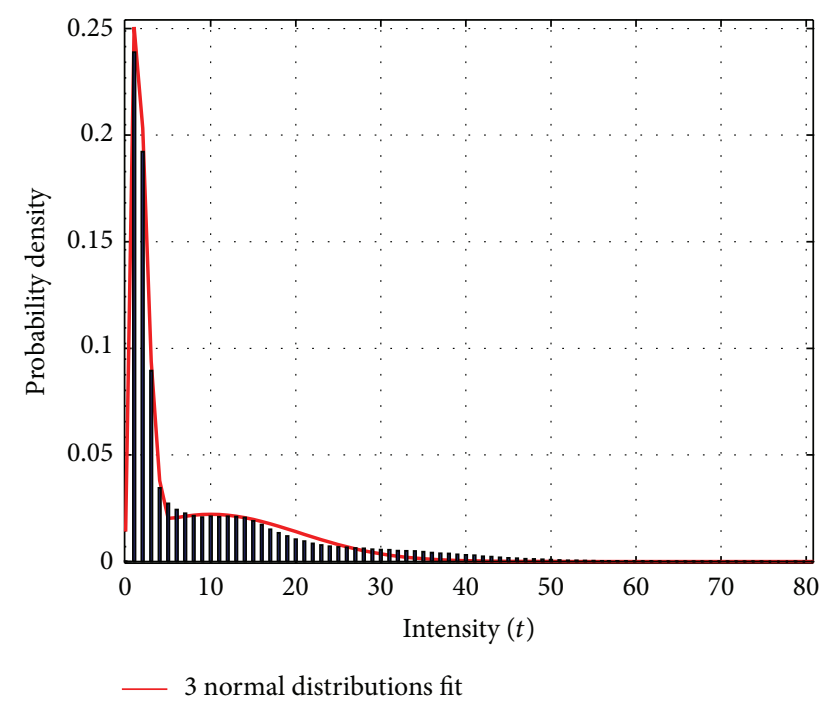

FIGURE 7: Three normal distributions fitted.

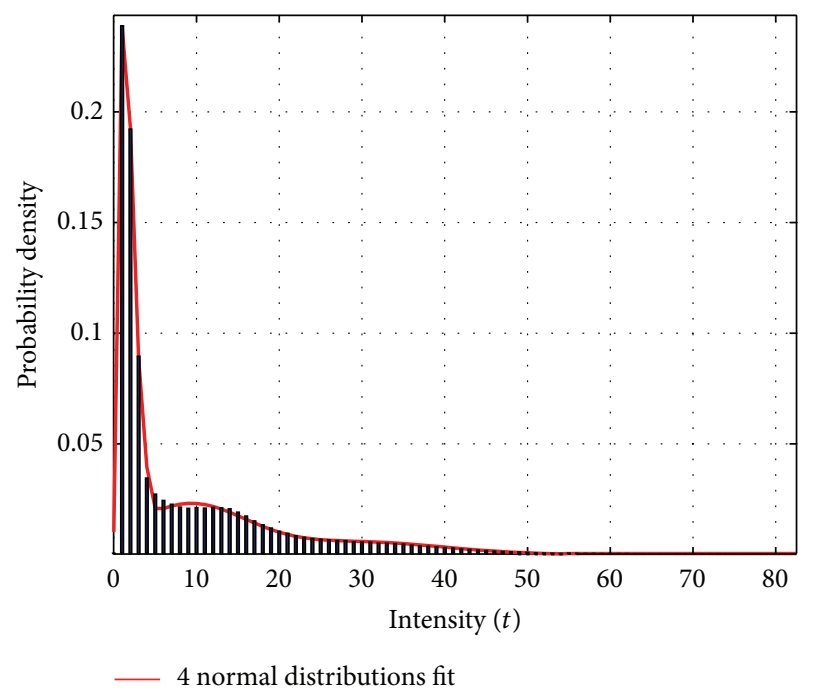

FIGURE 8: Four normal distributions fitted.

The analysis of the index of fit ( $R$-square) showed that the fitting results were the best with five normal functions and was the worst with a single normal function, while those with four, three, and two normal functions were intermediate between these two extremes. The fitting results with a single normal function could only fit the maximum peak value. The difference between the fitting result with five normal functions and four normal functions was very small because the vehicle types passing over Hangzhou Bay Bridge mainly comprised five types of vehicles, that is, two-axle, three-axle, four-axle, five-axle, and six-axle vehicles, and the four-axle, five-axle, and six-axle vehicles sometimes merged with each other in terms of the gross weight. The proportions of the other types of vehicles were very small, the frequencies of appearance were low, and the dispersion degree of the gross weight was very high. Thus, the main problem was to consider the probability distribution of the main vehicle types as

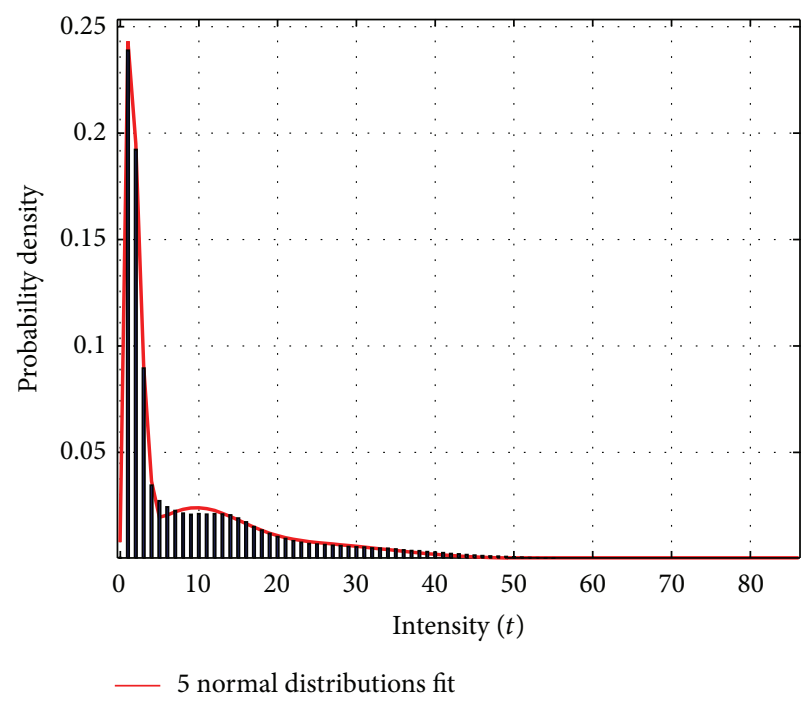

FIGURE 9: Five normal distributions fitted.

TABLE 2: Probability distribution parameters for the vehicle loads.

\begin{tabular}{lccccc}
\hline & Two-axle & Three-axle & Four-axle & Five-axle & $\begin{array}{c}\text { Six- or } \\
\text { more axle }\end{array}$ \\
\hline $\begin{array}{l}\text { Mean } \\
\text { value }\end{array}$ & 1.54 & 14.55 & 19.5 & 26.56 & 31.23 \\
$\begin{array}{l}\text { Standard } \\
\text { deviation }\end{array}$ & 1.01 & 5.92 & 7.89 & 11.75 & 11.84 \\
\hline
\end{tabular}

the basis of fitting. In addition, the fitting effect with more than five normal functions was better in the tail. However, the number of normal functions required for fitting should be tested case-by-case. If the reliability of the bridge needs to be studied, the fitting precision of the tail cannot be neglected.

The proportion of two-axle vehicles was $75.4 \%$, which included two-axle small cars, two-axle minivans, and twoaxle coaches. The proportion of three-, four-, five-, and sixor more axle vehicles was $7.5 \%, 5.8 \%, 4.5 \%$, and $6.8 \%$, respectively. The vehicle types that comprised two-axle vehicles were more frequent than others. The two-axle vehicles were characterized mainly by a multimodal distribution, which was similar to that shown in Figure 4 . Table 2 presents the mean values and standard deviations for the different types of vehicles.

3.2. Probability Characteristic of the Truck Loads. Truck load models are always used for the design and performance evaluations of bridges [20, 21]; thus it was necessary to consider the truck load on Hangzhou Bay Bridge. Table 3 shows the proportions of different vehicles in terms of their different load intensities. Two-axle vehicles were the most frequent when the load intensity was $<15 \mathrm{t}$. In general, these comprised two-axle minivans and two-axle large coaches when the gross weight was $>5 \mathrm{t}$. However, the basic models of trucks are all four-axle or more in the specifications [20, 21]; for example, the truck models in the American and Chinese specifications are both based on five-axle trucks. This is 
TABLE 3: Proportions of different vehicles in terms of different load intensities.

\begin{tabular}{lccccc}
\hline $\begin{array}{l}\text { Number of } \\
\text { axles }\end{array}$ & {$[5,10 t)$} & {$[10-15 t)$} & {$[15-20 t)$} & {$[20-25 t)$} & $>25 t$ \\
\hline 2 & $87.1 \%$ & $57.6 \%$ & $29.7 \%$ & $11.6 \%$ & $2.3 \%$ \\
3 & $10.8 \%$ & $22.5 \%$ & $28.2 \%$ & $25.7 \%$ & $6.4 \%$ \\
4 & $2.1 \%$ & $11.7 \%$ & $19.3 \%$ & $29.6 \%$ & $17.1 \%$ \\
5 & 0 & $5.1 \%$ & $10.4 \%$ & $15.6 \%$ & $25.8 \%$ \\
6 & 0 & $3.1 \%$ & $12.4 \%$ & $17.6 \%$ & $48.5 \%$ \\
\hline
\end{tabular}

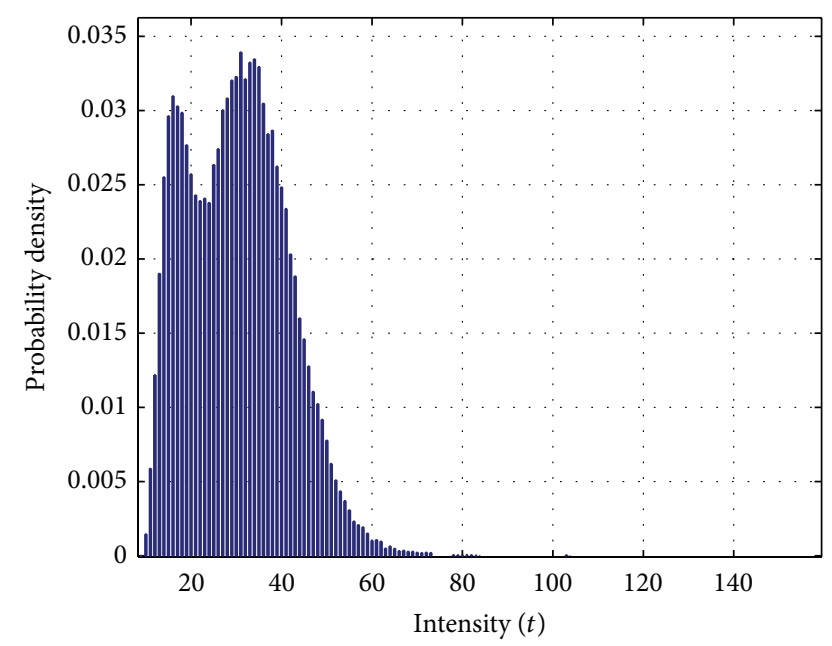

FIGURE 10: Histogram of five-axle (or more) trucks.

because large and heavy trucks have major effects on the safety of bridges. And many bridges were damaged by heavy trucks in recent years [22]. Therefore, a statistical rule based on five-axle (or more) trucks was employed in the present study.

According to the data collected, the numbers of fiveand six-axle trucks were 42,116 and 63,424, respectively, and the probability histogram is shown in Figure 10. It can be seen that the five-axle (or more) trucks exhibited multipeak characteristics with a main peak. Figures 11-13 show the results fitted with a normal distribution, log-normal distribution, and Weibull distribution, respectively. Although the fitting results for the curves all satisfied the $95 \%$ confidence intervals, the peak or tail sections were not fitted well by some curves and there were obvious offsets according to a visual analysis. It can be seen that the fitting results obtained with the normal distribution and Weibull distribution were all successful, but the fitting of the tail was better using a normal distribution, where the mean value was $29.38 \mathrm{t}$ and the coefficient of variation was $37.2 \%$.

3.3. Characteristic Vehicle Loads in the Morning and the Evening Rush Hour Periods. To determine the vehicle loads during the rush hour periods in the morning and the evening, the probability characteristics in different time intervals were analyzed. The traffic jam conditions on Hangzhou Bay Bridge during the morning and the evening rush hours, and

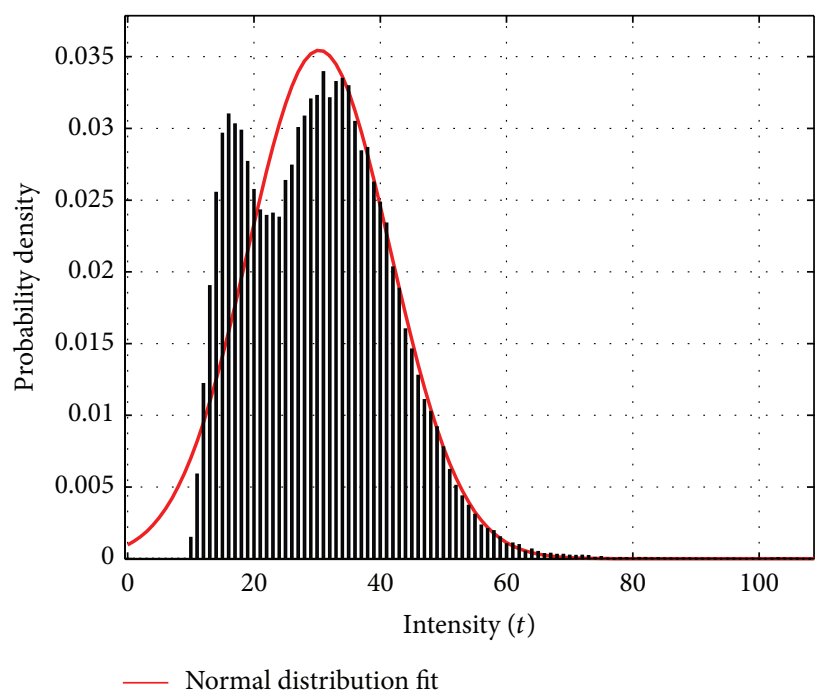

FIGURE 11: Normal distribution fitting.

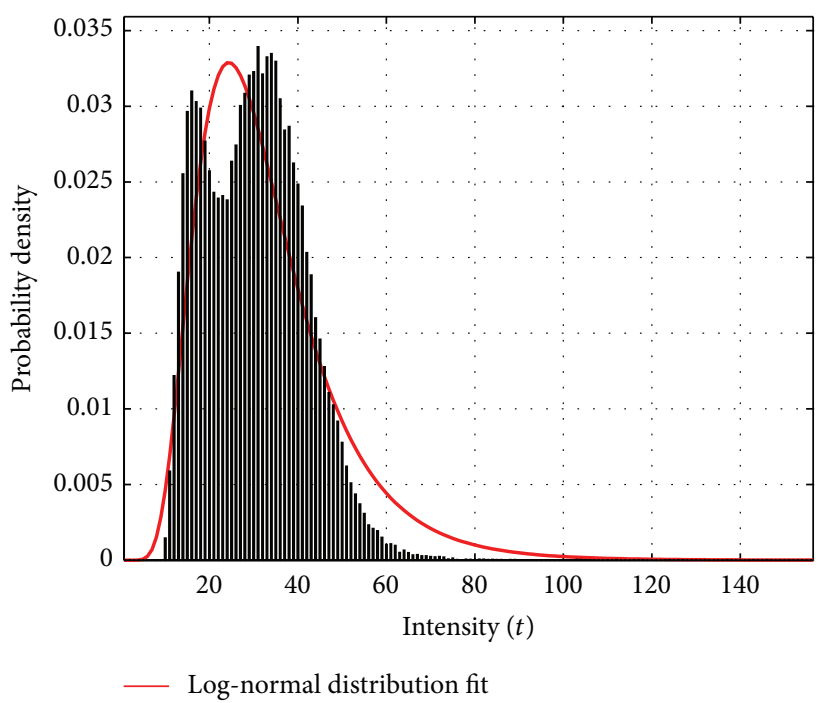

FIGURE 12: Log-normal distribution fitting.

the actual lane loads, were also compared based on the mean speed of vehicles. In general, the rush hour period in the morning occurred from 7:00 am to 9:00 am and the evening period lasted from 5:00 pm to 7:00 pm. Given the length of Hangzhou Bay Bridge, the morning rush hour period extended from 6:00 am to 9:00 am. Figure 14 shows the proportions of vehicles in the morning and the evening rush hour periods based on data mining, which demonstrate that the proportions of vehicles in the morning and the evening rush hour periods were approximately $20 \%$, and the highest level was $27 \%$, which indicates that the traffic was relatively even, but not high, and traffic jams did not form. Figure 15 shows the probability distribution and probability curve fitting for vehicles in the morning and the evening rush hour periods, which demonstrates that the probability distribution had multimodal characteristics, although they are not obvious. The first main peak was sharp and the other 


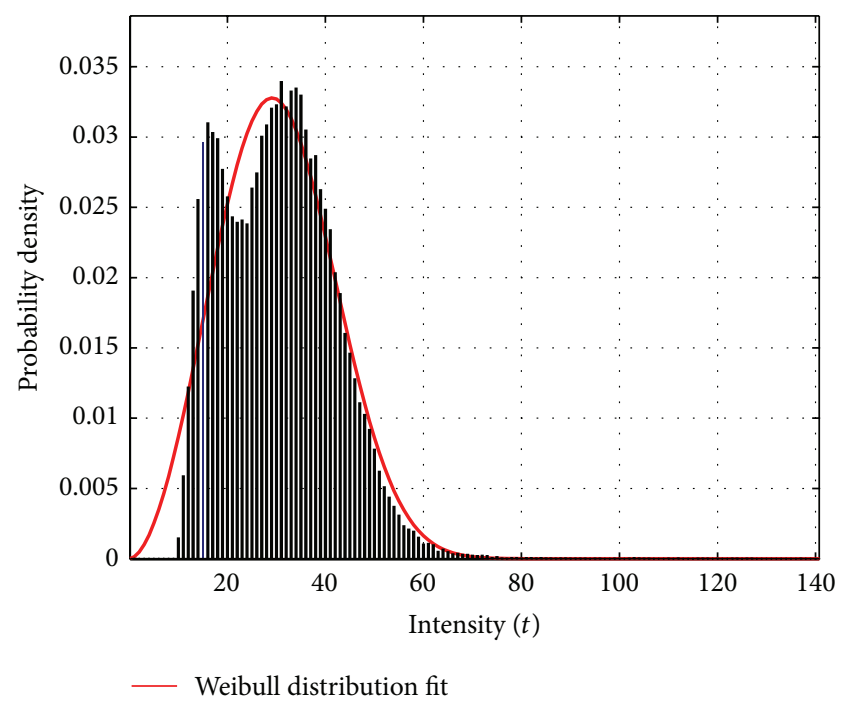

FIGURE 13: Weibull distribution fitting.

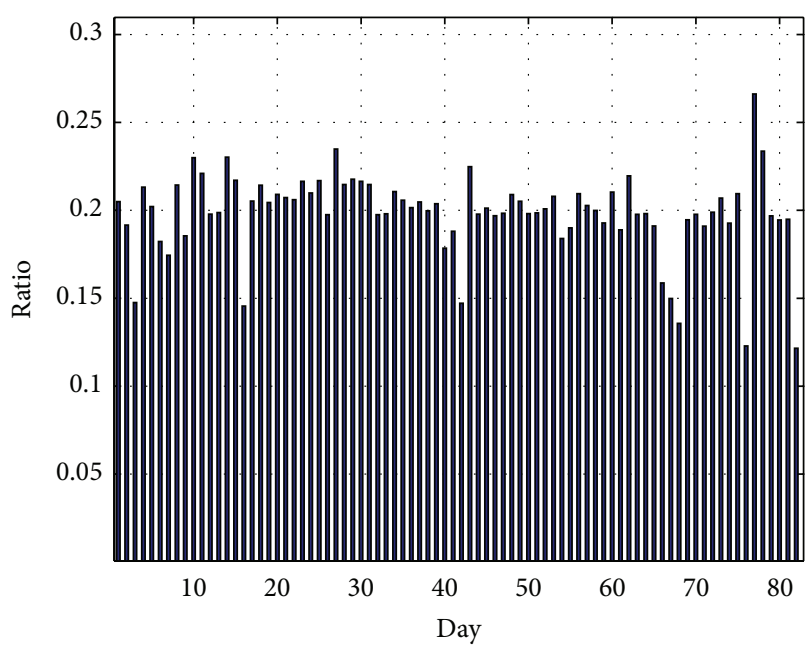

Figure 14: Proportions of vehicles in the morning and the evening rush hour periods.

peaks were relatively gradual. Thus, the superposition of three normal distribution functions was used for fitting. Figure 16 shows the proportions of different types of vehicles in the morning and the evening rush hour periods. It can be seen that two-axle vehicles (small cars and two-axle minivans or trucks) comprised most of the vehicles, that is, $77 \%$. To distinguish the proportions of small cars and two-axle minivans or trucks, Figure 17 shows the distribution of twoaxle vehicles at different load intensities. It can be seen that two-axle small cars of $<5 \mathrm{t}$ accounted for $>70 \%$ of the traffic and it is obvious that they formed the majority in the morning and the evening rush hour periods.

The embedded WIM system was located close to a charging station near south entrance; thus the speed of most of the vehicles was relatively low, that is, about $20 \mathrm{~km} / \mathrm{h}$ in about $90 \%$ of the cases. Therefore, we could not analyze

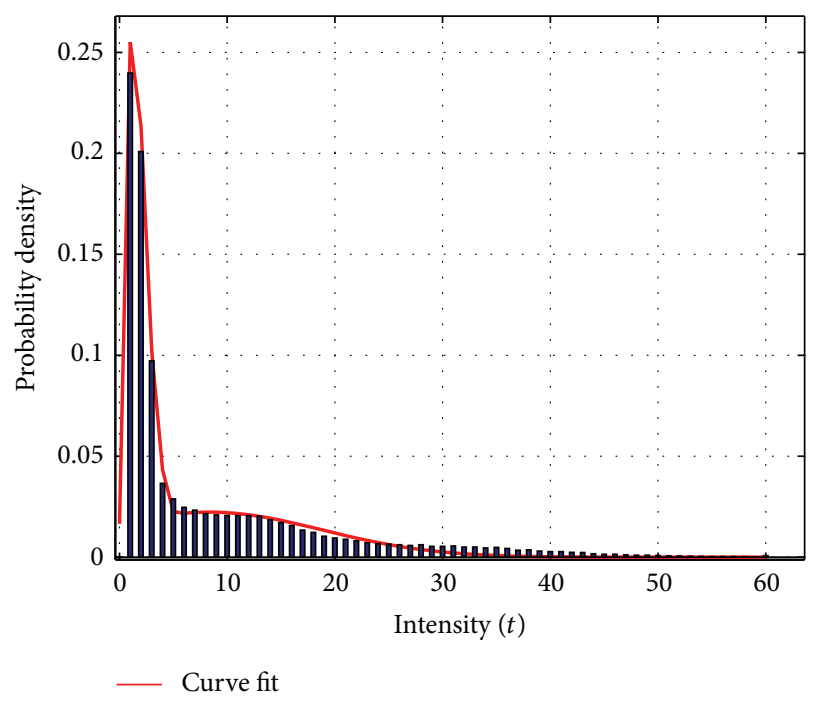

FIGURE 15: Histogram and curve fitting results for vehicle loads in the morning and the evening rush hour periods.

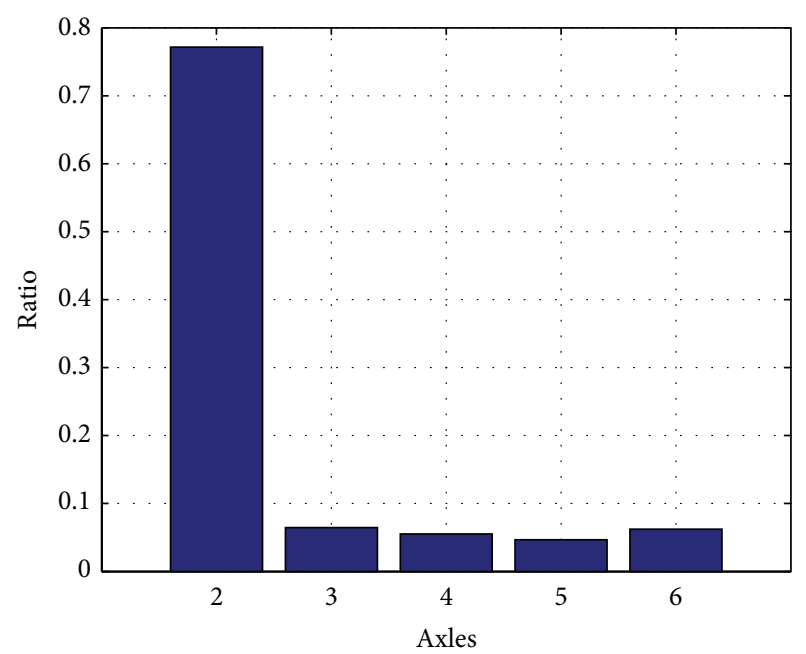

FIgURE 16: Proportions of vehicles with different axle types.

the actual speed and traffic jam condition for vehicles based on the speed measured at the Hangzhou Bay Bridge WIM site.

\section{Distribution of the Maximum Value of Trucks during the Reference Design Period}

The analysis requires the solution of the maximum problem when the maximum truck load is needed during the reference design period for a bridge. A previous study [23] showed that the truck load is a time-varying random process, which can be modeled as Poisson processes, the intensities of which are also time-dependent variables where the average occurrences can be calculated using a Poisson distribution. Given an average 


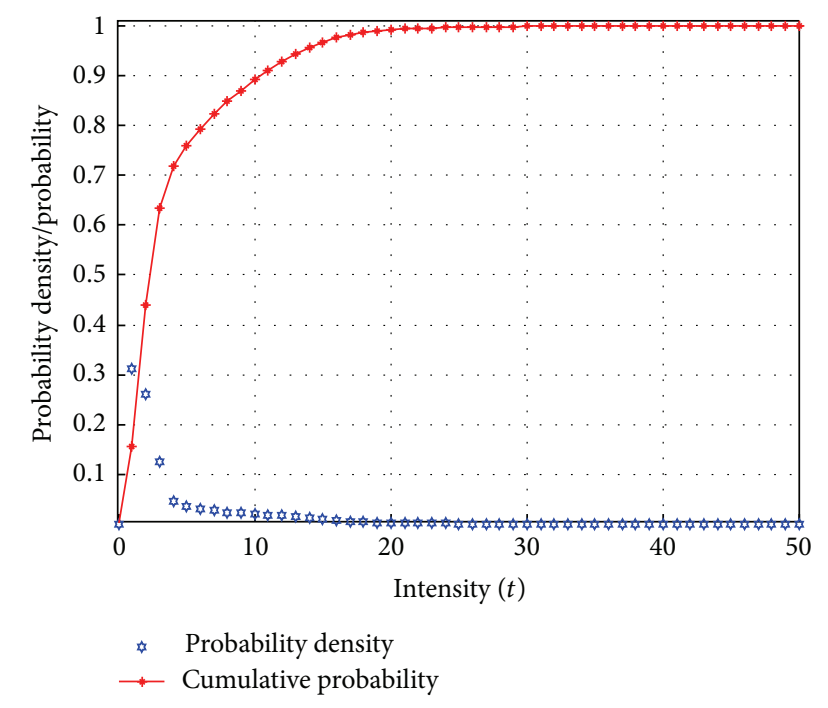

FIGURE 17: Different load distributions of two-axle vehicles.

rate of occurrence $\lambda$, the probability of $n$ events occurring within a time interval, $p(n)$ is given by

$$
p(n)=e^{-\lambda t} \frac{(\lambda t)^{n}}{n !},
$$

where $t$ is the time interval and $n=0,1,2, \ldots$

Based on the Poisson process and the load characteristics, the following hypothesis can be proposed.

(1) The truck loads during the bridge service life are completely random and the time interval of an event is very small relative to the overall bridge life.

(2) The truck loads are also random and statistically time independent during each interval $t$.

(3) The probability of each event during a time interval is an incremental process and the possibility of the reoccurrence of the event in a time interval is negligible.

According to the Poisson process, the truck load in each time interval can be considered independent and the intensity distributions are all the same. And in order to simplify the calculation, each time interval is supposed to be equal during the bridge service life and there is no overlap between each interval $t$. According to reliability theory [24], the maximum truck load during the reference design period of the bridge can agree with the following hypothesis. If supposing that $Q_{i}$ $(i=1,2, \ldots, N)$ is the load intensity in the $i$ th time interval and $Q_{T}$ is the load intensity in reference design period $T$, the problem of determining the maximum value for the trucks becomes the problem of finding the maximum $Q_{T}$ from $N$ independent $Q_{i}$, that is, $\max \left(Q_{1}, Q_{2}, \ldots, Q_{N}\right)$, which is as follows:

$$
\begin{aligned}
P\left(Q_{T} \leq q\right) & =P\left(\text { all } Q_{i} \leq q\right) \\
& =P\left(Q_{1} \leq q \cap Q_{2} \leq q \cap \cdots \cap Q_{N} \leq q\right) .
\end{aligned}
$$

According to the above hypothesis of an independent identical distribution, the following equation is obtained:

$$
\begin{aligned}
& P\left(Q_{1} \leq q \cap Q_{2} \leq q \cap \cdots \cap Q_{N} \leq q\right) \\
& \quad=P\left(Q_{1} \leq q\right) \cdot P\left(Q_{2} \leq q\right) \cdots P\left(Q_{N} \leq q\right) .
\end{aligned}
$$

Suppose that the cumulative probability distribution of the truck load in each time interval is $F_{Q}(q)$ and the maximum cumulative probability distribution in $T$ is $F_{\mathrm{Q}_{T}}(q)$; then $F_{\mathrm{Q}_{T}}(q)$ can be written as

$$
F_{\mathrm{Q}_{T}}(q)=F_{\mathrm{Q}_{1}}(q) \cdot F_{\mathrm{Q}_{2}}(q) \cdots F_{\mathrm{Q}_{N}}(q)=\left[F_{\mathrm{Q}}(q)\right]^{N} .
$$

Its probability density is

$$
f_{\mathrm{Q}_{T}}(q)=N \cdot f_{\mathrm{Q}}(q) \cdot\left[F_{\mathrm{Q}}(q)\right]^{N-1}
$$

where $N$ is an integer.

In the uniform standard of structural reliability design employed in Chinese highway engineering (GB50068-2001) [25], the maximum load distribution in $t$ (one time interval) is considered to be the section distribution of the vehicle load, and the maximum distribution of the load in $100 \mathrm{t}$ is considered to be the maximum value distribution of the vehicle loads during the reference design period (the reference design period is 100 years of Hangzhou bay bridge), which agrees with (6). However, the problem is that a suitable value of $t$ is related to the data quantity and the data quality. Good quality indicates that the stability of the data is relatively good, which means that the variations in the mean value and standard deviation of the data are within the allowable range. Nowak [6] collected data over more than 2 weeks, including 9,250 heavy trucks, and determined the maximum truck load within 75 years by extrapolating the probability distribution over time. Therefore, by combining the reliable statistical data obtained in the present study and the research reported by Nowak, we tested intervals $t$ of 1 week or 2 weeks, which both showed good applicability.

Based on more than 3 months of data and the probability distribution, using (6), the basic distributions for $t$ intervals of 1 week and 2 weeks were obtained as follows:

$$
F_{\mathrm{Q}_{t}}(q)=\left[F_{\mathrm{Q}_{N}}(q)\right]^{t / N} \text {. }
$$

Figures 18 and 19 show the distributions with different time intervals, $t$.

During the extrapolation process, a problem that needed to be considered is the accuracy of the probability distribution in the tail fitted to the data collected. The tail reflects the distribution of heavy trucks; thus the error would be amplified when extrapolating using (6) if handled inappropriately. It should be mentioned that using the load distributions of all vehicle loads (including different axle weights, i.e., two-axle, three-axle, four-axle, or more) is not suitable for solving the maximum value of the vehicle loads. This will cause the fitted results to shift to the peak range, thereby neglecting the tail characteristics, which are important for the maximum value distribution calculation. Therefore, the probability characteristics of the truck load were analyzed 


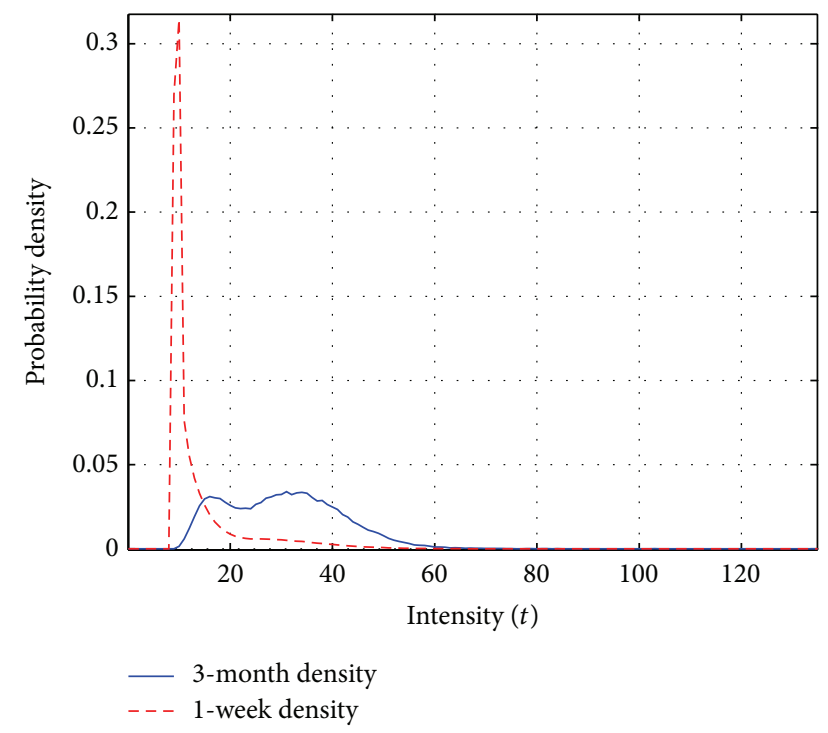

FIgURE 18: Probability density in 1 week.

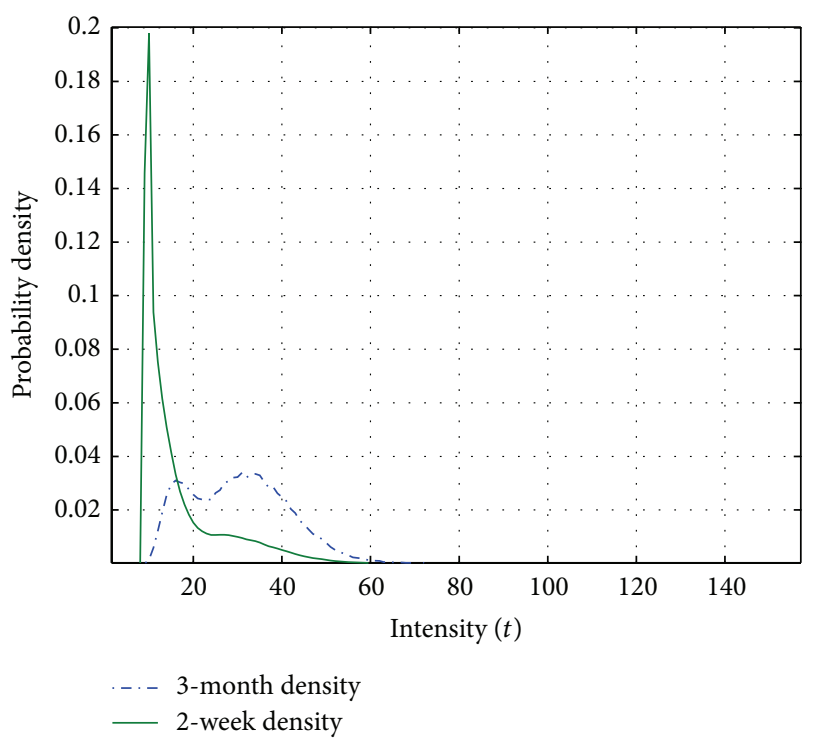

FIgURe 19: Probability density in 2 weeks.

independently in the section above; thus the probability distribution of the truck load reflects the tail features of the statistical distribution and it can be used to analyze the maximum value distribution.

According to (6) and (8), the mean value of the maximum truck load during the reference design period of the bridge is as follows:

$$
\begin{gathered}
X_{\text {mean }}=\int_{x_{\text {min }}}^{x_{\max }} x \cdot f_{\text {max }}(x) d x, \\
\sigma^{2}=\int_{x_{\text {min }}}^{x_{\max }}\left(x-X_{\text {mean }}\right)^{2} \cdot f_{\text {max }}(x) d x .
\end{gathered}
$$

Figure 20 shows the distribution of the maximum truck load during the reference design period. According to (9),

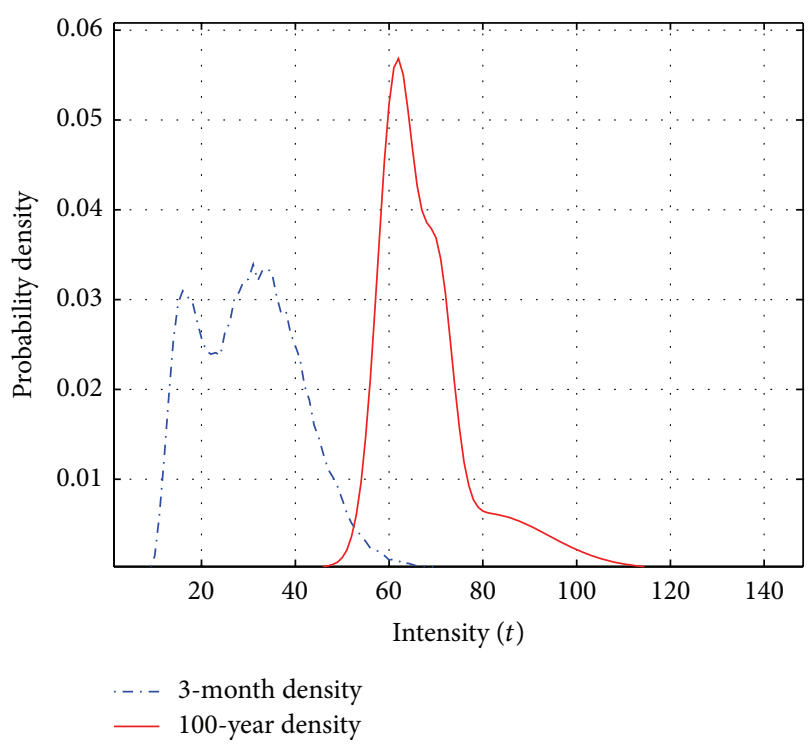

FIgURE 20: Maximum value distribution of the truck loads during the reference design period.

the mean value of trucks can be up to $65.0 \mathrm{t}$, with a standard deviation of $10.6 \mathrm{t}$ and a coefficient of variation of $16.3 \%$.

\section{Conclusions}

In this study, a statistical analysis of the vehicle loads on Hangzhou Bay Bridge was performed based on WIM data collected for more than 3 months. The following conclusions can be made.

(1) The statistical analysis of all the vehicle samples showed that the mean values of the vehicle loads were relatively concentrated and the coefficients of variation were not high. The vehicle load comprised different types of vehicles, thus it was obviously characterized by a multimodal distribution. The fitting results were best using five normal functions, probably because the vehicles that passed over Hangzhou Bay Bridge mainly belonged to five types. And the occurrence frequencies of other types of vehicles were low and the dispersion of the gross weight was high.

(2) The probabilistic characteristics of trucks with five axles (or more) were analyzed independently and the results showed that a normal distribution fitted well to the peak and tail. The mean value was 29.38 tons and the coefficient of variation was $37.2 \%$. Thus, a normal distribution can be used to describe the probability distribution of the truck load.

(3) A statistical analysis of the vehicle loads in the morning and the evening rush hour periods was also performed, where the results showed that the vehicles mainly comprised small cars in these periods, which could be fitted approximately using three normal distribution functions. 
(4) Only the truck load samples were used to analyze the maximum value of the truck load, rather than all the vehicle samples. The tail fitting of the histogram agreed well with the probability distribution of the truck load. Because sufficient data were available, the inverse method was used to determine the value of the basic time interval by referring to previous research. The results showed that the mean value of the maximum truck load in 100 years would be up to 65.0 tons with a coefficient of variation of $16.3 \%$.

\section{Disclaimer}

The results and conclusions presented in the paper are of authors' and do not necessarily reflect the view of the sponsors.

\section{Conflict of Interests}

The authors declare that there is no conflict of interests regarding the publication of this paper.

\section{Acknowledgments}

This study is jointly funded by Basic Institute Scientific Research Fund (Grant no. 2012A02), the National Natural Science Fund of China (NSFC) (Grant no. 51308510), and Open Fund of State Key Laboratory Breeding Base of Mountain Bridge and Tunnel Engineering (Grant nos. CQSLBFY14-15 and CQSLBF-Y15-5).

\section{References}

[1] Y. J. Ge, "Technical challenges and refinement research on wind resistance of long-span bridges," Engineering Mechanics, vol. 28, no. 2, pp. 11-23, 2011 (Chinese).

[2] http://baike.so.com/doc/2827423.html.

[3] http://baike.so.com/doc/1780273.html.

[4] T.-H. Yi, H.-N. Li, and M. Gu, "Wavelet based multi-step filtering method for bridge health monitoring using GPS and accelerometer," Smart Structures and Systems, vol. 11, no. 4, pp. 331-348, 2013.

[5] H.-N. Li, T.-H. Yi, M. Gu, and L.-S. Huo, "Evaluation of earthquake-induced structural damages by wavelet transform," Progress in Natural Science, vol. 19, no. 4, pp. 461-470, 2009.

[6] A. S. Nowak, "Calibration of LRFD bridge design code," NCHRP Rep. 368, Transportation Research Board of the National Academies, Washington, DC, USA, 1999.

[7] F. Moses, Calibration of Load Factors for LRFR Bridge Evaluation, NCHRP 454, Transportation Research Board, National Research Council, Washington, DC, USA, 2001.

[8] G. K. Fu and J. You, "Truck loads and bridge capacity evaluation in China," Journal of Bridge Engineering, vol. 14, no. 5, pp. 327335, 2009.

[9] G. K. Fu and J. You, "Extrapolation for future maximum load statistics," Journal of Bridge Engineering, vol. 16, no. 4, pp. 527535, 2011.

[10] E. J. Obrien, B. Enright, and A. Getachew, "Importance of the tail in truck weight modeling for bridge assessment," Journal of Bridge Engineering, vol. 15, no. 2, pp. 210-213, 2010.
[11] P. Chotickai and M. D. Bowman, "Truck models for improved fatigue life predictions of steel bridges," Journal of Bridge Engineering, vol. 11, no. 1, pp. 71-80, 2006.

[12] J. Zhao and H. Tabatabai, "Evaluation of a permit vehicle model using weigh-in-motion truck records," Journal of Bridge Engineering, vol. 17, no. 2, pp. 389-392, 2012.

[13] G. Mei, Q. Qin, and D. J. Lin, "Bi-modal probabilistic model of highway and bridge vehicle loads," Journal of Tsinghua University, vol. 43, no. 10, pp. 1394-1404, 2003 (Chinese).

[14] X. M. Zong, D. L. Hu, and J. Gao, "Vehicle's overload and limiting load standard for bridge safety," Journal of Changan University, vol. 28, no. 1, pp. 60-65, 2008 (Chinese).

[15] T. Guo, A. Q. Li, and D. L. Zhao, "Multiple-peaked probabilistic vehicle load model for highway bridge reliability assessment," Journal of Southeast University (Natural Science Edition), vol. 38, no. 5, pp. 763-766, 2008 (Chinese).

[16] J. X. Gong, W. J. Li, J. L. Zhao et al., "Research on probabilistic model of highway bridge vehicle loads (1)-non-controlling area," Journal of Highway and Transportation Research and Development, vol. 27, no. 6, pp. 40-45, 2010 (Chinese).

[17] Z. F. Xu, Q. Wang, and Y. S. Liu, "Research of vehicle load model for highway bridges in Guangdong Province based on WIM data," Bridge Construction, vol. 42, no. 6, pp. 39-44, 2012 (Chinese).

[18] S. W. Sun and L. M. Sun, "Statistic model of vehicle loads for highway bridges," Journal of Tongji University (Natural Science), vol. 40, no. 2, pp. 198-204, 2012 (Chinese).

[19] J. Pelphrey, C. Higgins, B. Sivakumar et al., "State-specific LRFR live load factors using weigh-in-motion data," Journal of Bridge Engineering, vol. 13, no. 4, pp. 339-350, 2008.

[20] PR China Ministry of Communications, "General code for design of highway bridges and culverts," Tech. Rep. JTG D602004, China Communications Press, Beijing, China, 2004, (Chinese).

[21] AASHTO LRFD Bridge Design Specifications, AASHTO, Washington, DC, USA, 4th edition, 2007.

[22] D. Z. Sun, Study on multiple hazards design theory for bridge under earthquakes and heavy truck loads [Ph.D. thesis], Department of Lifeline Engineering, Institute of Engineering Mechanics, China Earthquake Administration, Harbin, China, 2012 (Chinese).

[23] S. E. Hida, "Statistical significance of less common load combinations," Journal of Bridge Engineering, vol. 12, no. 3, pp. 389393, 2007.

[24] T. T. Soong, Fundamentals of Probability and Statistics for Engineers, State University of New York at Buffalo, Buffalo, NY, USA, 2004.

[25] P.R. China Ministry of Communications, GB50068-2001, Unified Standard for Reliability Design of Building Structures, China Communications Press, Beijing, China, 2002, (Chinese). 

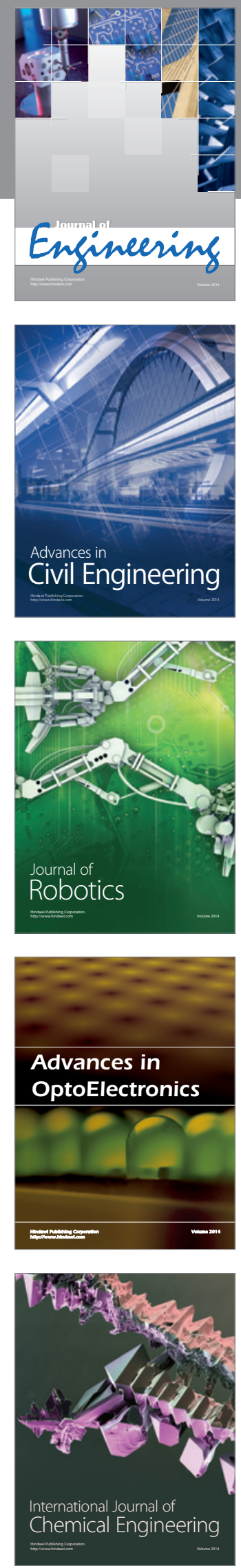

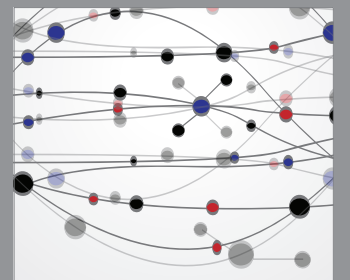

The Scientific World Journal
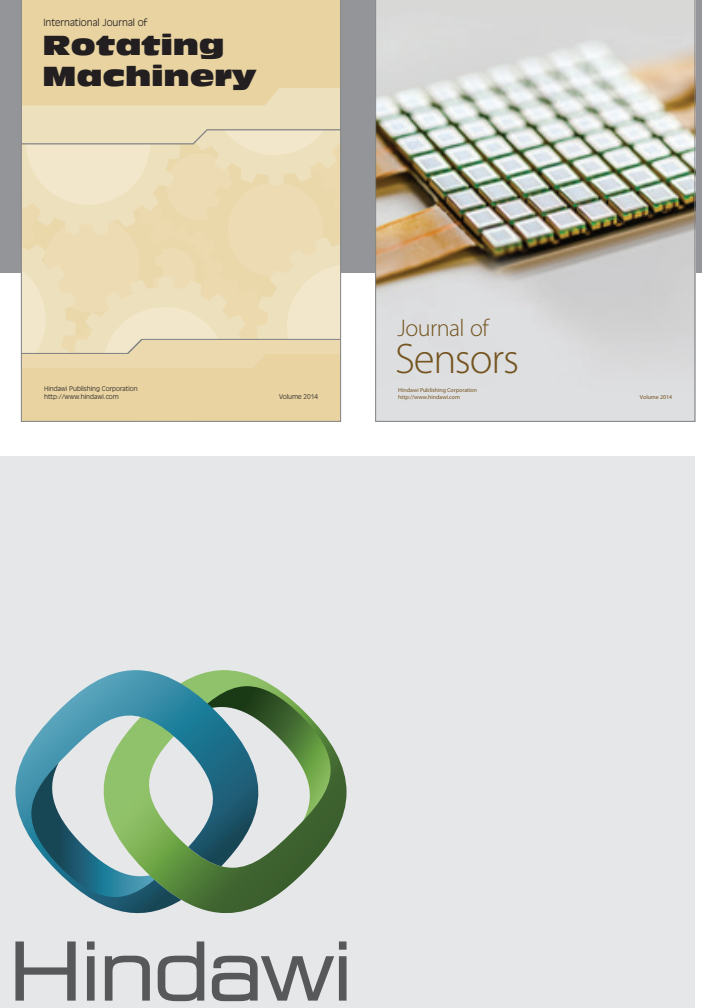

Submit your manuscripts at http://www.hindawi.com
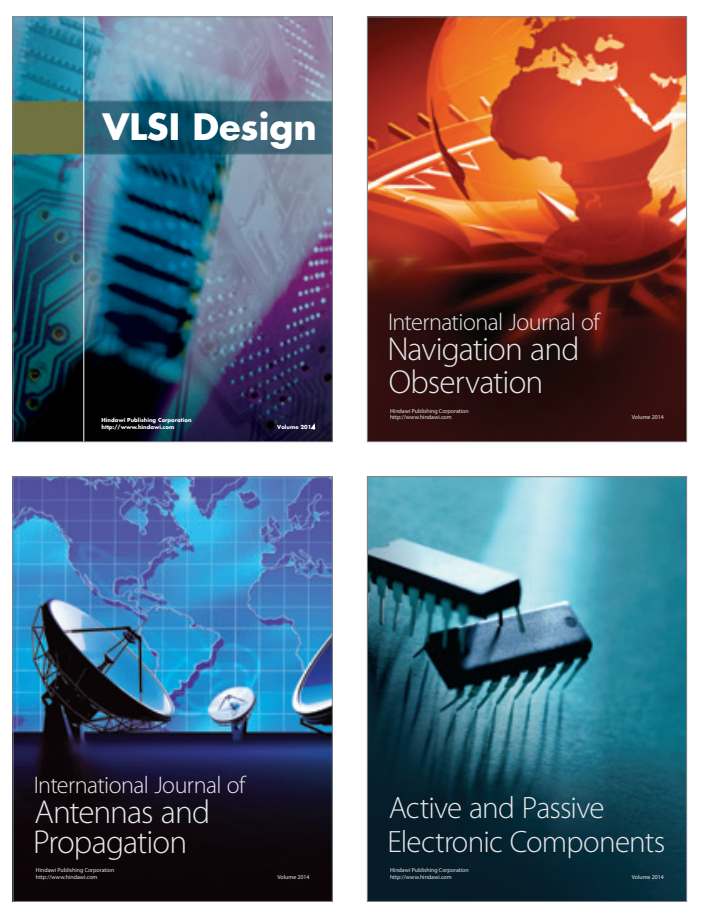
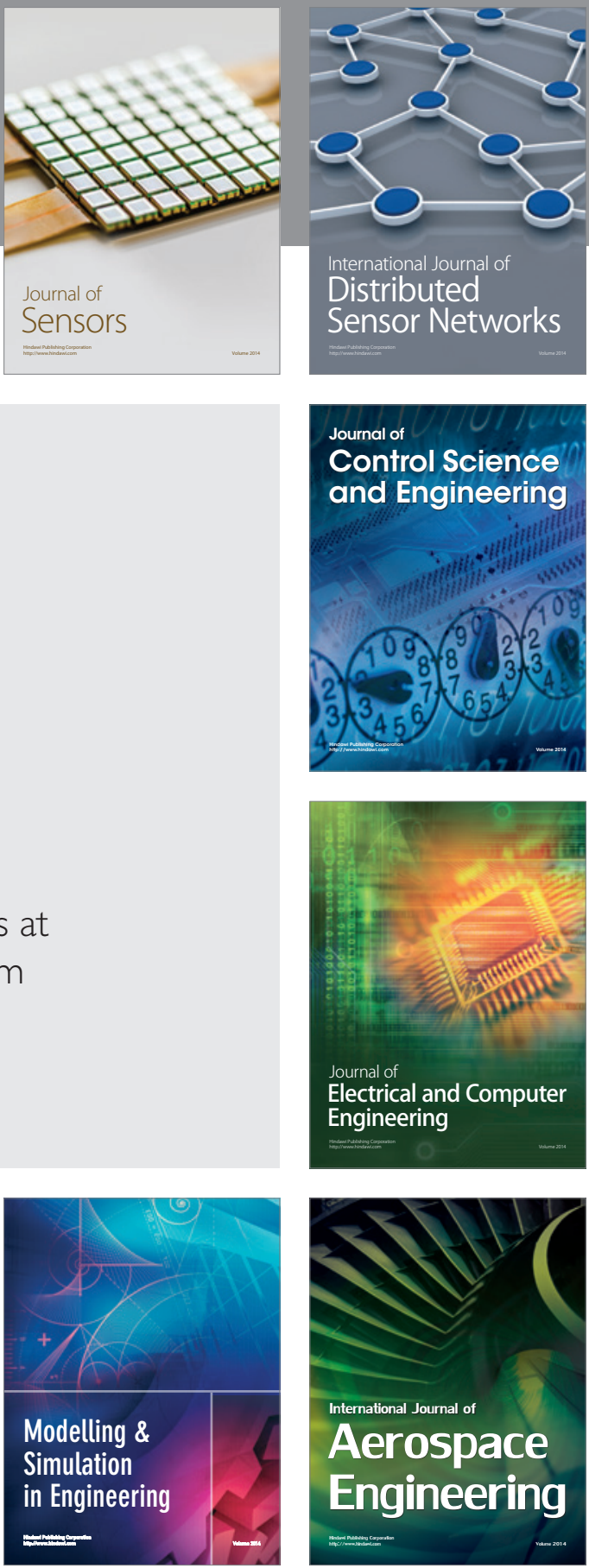

Journal of

Control Science

and Engineering
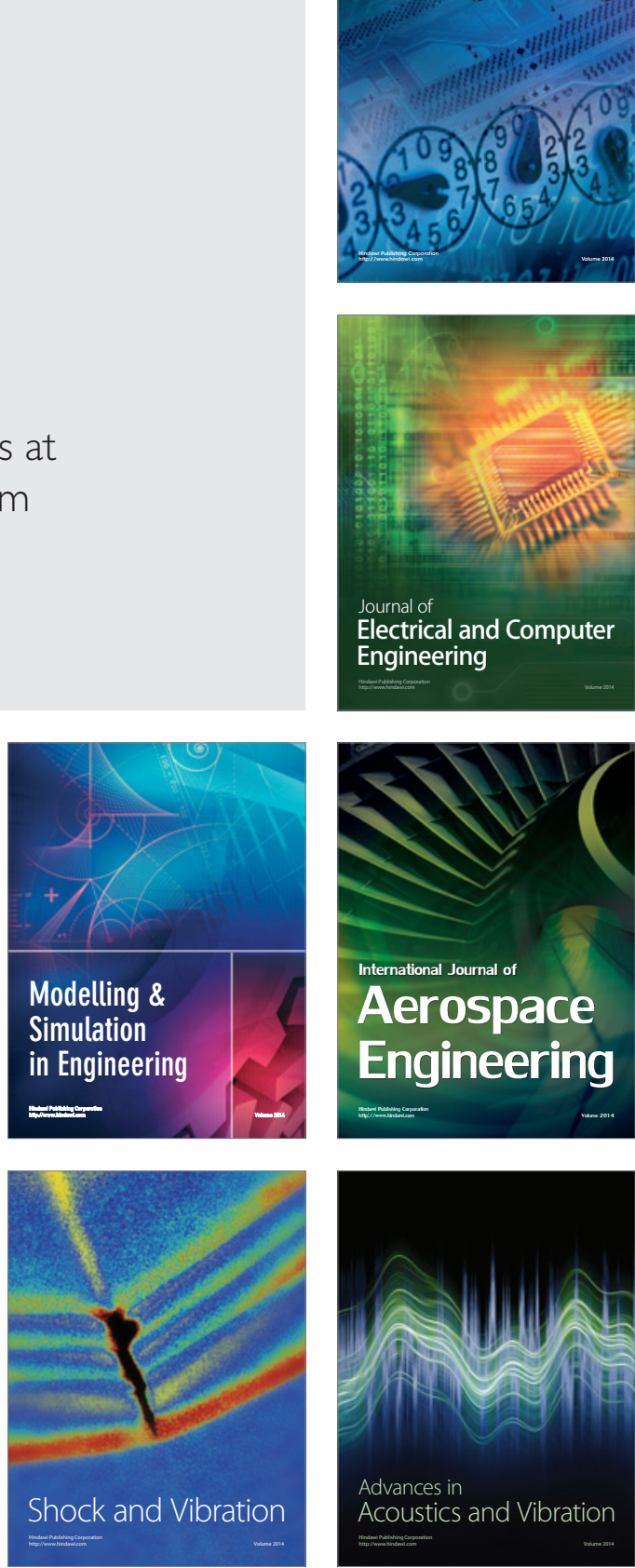